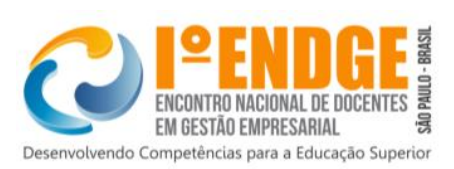

Área Temática: Didática do Ensino Superior

\title{
Gestão de Tecnologias na Educação: experiência na formação de graduandos em Computação
}

\author{
Daniel Costa de Paiva - profdanielpaiva@gmail.com \\ Universidade Federal Fluminense (UFF) e Instituto do Noroeste Fluminense de \\ Educação Superior (INFES) \\ Francisco de Assis Silva Oliveira - francisco25aoliveira@ hotmail.com \\ Universidade Federal Fluminense (UFF) e Instituto do Noroeste Fluminense de \\ Educação Superior (INFES)
}

\section{Resumo}

Este trabalho apresenta a adaptação realizada na disciplina de Gestão de Tecnologias na Educação levando em consideração as recomendações da meta 16 do Plano Nacional de Educação. São discutidas as formas de abordagem, organização do conteúdo teórico e as atividades propostas que os alunos precisaram executar. A viabilidade e os resultados obtidos demonstram maior engajamento, pois ampliou o leque de conhecimento de alternativas aplicáveis.

Palavras-chave: gestão, formação, tecnologias

\begin{abstract}
This paper presents the adaption of the discipline Technology Management in Education to take into account the recommendations of the goal 16 of National Education Plan. This paper have the content presentation form and the proposed activities for the students. The feasibility of the approaches and the results show students more engaged and that the real-life experiences contributed for the range of applicable alternatives.
\end{abstract}

Keywords: tecnology, management. 


\section{Introdução}

"Há cerca de vinte anos, as principais plataformas de comunicação e os aparatos tecnológicos eram bem diferentes" (DAMASCENO, 2015). No atual contexto é preciso orientar os alunos sobre onde buscar as informações, como tratá-las e como utilizá-las. O processo de aquisição de informações exige profissionais críticos, criativos, com capacidade de pensar e trabalhar em grupo (MERCADO, 2002).

Como pode ser visto há uma diferença importante na facilidade de acesso às informações e no tratamento das mesmas. Atualmente, o uso inovador da tecnologia aplicado à educação é uma realidade e deve estar apoiado, segundo o MEC [2007] em uma filosofia de aprendizagem que proporcione aos estudantes efetiva interação no processo de ensino-aprendizagem. Afinal, o "aprendizado diário (...) depende da transmissão dos conhecimentos de uma geração para outra, ou seja, de uma cultura base para as transformações internas e para as adequações que o mundo exterior necessita" (BROUGERE, 2000).

Especialmente em atividades de gestão, gerações diferentes atuam no mesmo ambiente e a maioria dos diretores e professores conviveu por todo o tempo de sua formação, até a graduação, em um cenário sem tecnologias e agora precisam instruir, dar aulas, para nativos digitais (WPENSAR1; WPENSAR2, 2015). Estes últimos familiarizados com as tecnologias que podem facilitar o dia a dia dos gestores.

Este trabalho apresenta um relato de experiência na disciplina Gestão de Tecnologias na Educação, do curso de Computação, que teve sua abordagem alterada na busca por atuar frente às dificuldades mencionadas, ao problema da falta de formação específica da área de gestão, e da diversidade de pontos de vista e de gerações no ambiente de trabalho. Outra inspiração para adaptações foi a meta 16 do Plano Nacional de Educação (PNE) como incentivo de iniciação à formação de gestores, considerando as necessidades, demandas e contextualizações dos sistemas de ensino e da região (PNE).

Apesar de existirem trabalhos desenvolvidos no sentido de formar e treinar gestores (MARINHO et al., 2011), a diferença apresentada aqui se dá nas atividades propostas aos acadêmicos que envolveram maior contato com as instituições da região de Santo Antônio de Pádua, no estado do Rio de Janeiro.

Houve incentivo para a busca por documentação, debate com um gestor e os alunos propuseram soluções para cenários realistas do ensino básico, técnico e superior.

Na próxima seção está o relato de experiência detalhado indicando as atividades propostas e os resultados obtidos. Por fim, as considerações finais que buscam uma síntese para fomentar a discussão a respeito das estratégias adotadas e da adaptabilidade a outros cenários.

\section{Gestão de Tecnologias na Educação}

A ementa da disciplina Gestão de Tecnologias na Educação foi adaptada levando em conta os objetivos da Meta 16 do Plano Nacional de Educação (PNE) que visa favorecer a construção do conhecimento e a valorização da cultura da investigação e atuar junto à formação de futuros gestores.

A disciplina foi organizada de forma a alternar atividades de exposição de conteúdo com atividades de fixação e aprimoramento. Durante o período letivo foram abordados conteúdos relativos a planejamento e problemas, conflitos e negociação, diferenças entre chefe e líder, tipos de gestão e mais especificamente relacionados com o ambiente educacional, gestão escolar e gestão de tecnologias na educação.

Dentre os conteúdos teóricos abordados, primeiro foi apresentado o planejamento do período letivo, seguindo de documentação, legislação e organograma, quando foi solicitado que os alunos buscassem informações do Projeto Político Pedagógico e do Organograma das escolas da 


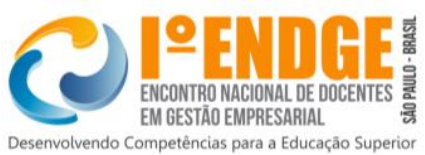

região, através dos quais, foram discutidas questões sobre atividades realizadas e funções desempenhadas no ambiente escolar.

A seguir foi apresentado conteúdo a respeito de atividades inerentes aos gestores, como planejamento, problemas, conflitos e negociação, enfatizando as diferentes gerações que precisam atuar em conjunto. Foi ressaltado que não são apenas aspectos de idades e experiências de vida, mas também atuação em áreas do conhecimento diferentes, o que naturalmente incorre em desafios para a comunicação. Aos alunos foi solicitado que fizessem a leitura e análise crítica de livros relacionados aos assuntos, os quais foram apresentados e discutidos em seminários. Os diferentes tipos de gestão - de recursos, de tempo e de pessoas foram apresentados antes de abordar a gestão escolar propriamente dita.

Além disso, foram propostas quatro dinâmicas e atividades durante o curso, que serão detalhadas mais adiante: (1) visita do diretor de uma escola estadual, (2) proposta de um organograma e tecnologias para todos os setores e pessoas envolvidas em uma escola. (3) montagem de quebra-cabeça (atividade gamificada para trabalho em grupo e ações de gestão de pessoas e recursos) (4) proposta de um curso de extensão na modalidade de ensino à distância.

Para a primeira atividade foi convidado o diretor de uma escola estadual, que oferece formação básica de ensino, fundamental e médio, primeiro ele fez uma exposição sobre o dia a dia, principais problemas e burocracias e a seguir ocorreu um debate sobre a atuação profissional e as principais dificuldades inerentes a um gestor na região. Ao final, o diretor ficou disponível para sanar as dúvidas dos alunos e muitas perguntas foram feitas e respondidas.

A segunda atividade foi solicitar que os alunos obtivessem ou elaborassem e estudassem organogramas e projetos político-pedagógicos reais de escolas da cidade e, com base no conhecimento adquirido, propusessem um organograma "ideal" para uma escola fictícia. De posse deste organograma elaborado, eles deveriam propor conjuntos de tecnologias a serem utilizadas para auxiliar no trabalho executado em todos os setores e por todas as pessoas nas atribuições de seus cargos.

Tais abordagens deveriam levar em consideração dois cenários imaginários: um primeiro, onde a escola dispõe de recurso financeiro para a aquisição de equipamentos, softwares e tudo o que os alunos propusessem e, outro cenário, que leva em conta a inexistência de recurso financeiro disponível e a dificuldade para se conseguir tais recursos, cuja solução seria a utilização de tecnologias de custo zero. Estas propostas foram apresentadas em dois dias diferentes.

Para a terceira dinâmica a turma foi dividida em dois grupos (A e B) e cada um deles recebeu um quebra-cabeça de 500 peças para montagem em um período de aula. Cada grupo deveria montar o mais rápido possível e para isso, as funções deveriam ser distribuídas entre os integrantes.

Para aumentar a dificuldade, foram inseridos desafios gamificando a atividade, por exemplo, uma peça de cada quebra-cabeça foi trocada com o outro grupo com o conhecimento de apenas um aluno de cada grupo, e um integrante foi trocado entre os grupos A e B durante a montagem. Outra dificuldade foi a retirada de uma peça de cada quebra-cabeça para posterior avaliação dos impactos e correlação com o cotidiano da atividade profissional.

Ao final eles deveriam entregar um relato individual contendo: a função desempenhada por cada membro da equipe, a descrição do resultado da troca de integrantes e da troca e falta de peças do quebra-cabeça. De acordo com isso, a equipe vencedora, ou a que terminasse primeiro, deveria distribuir o total de 2 pontos entre os integrantes.

Os alunos tiveram que fazer uso de habilidades administrativas, trabalho em grupo e habilidades sociais, delegação de funções, divisão de tarefas, solução de problemas, definição de estratégias, melhoria da comunicação e integração entre os alunos. Os resultados obtidos por cada um dos grupos estão apresentados na figura 1. 


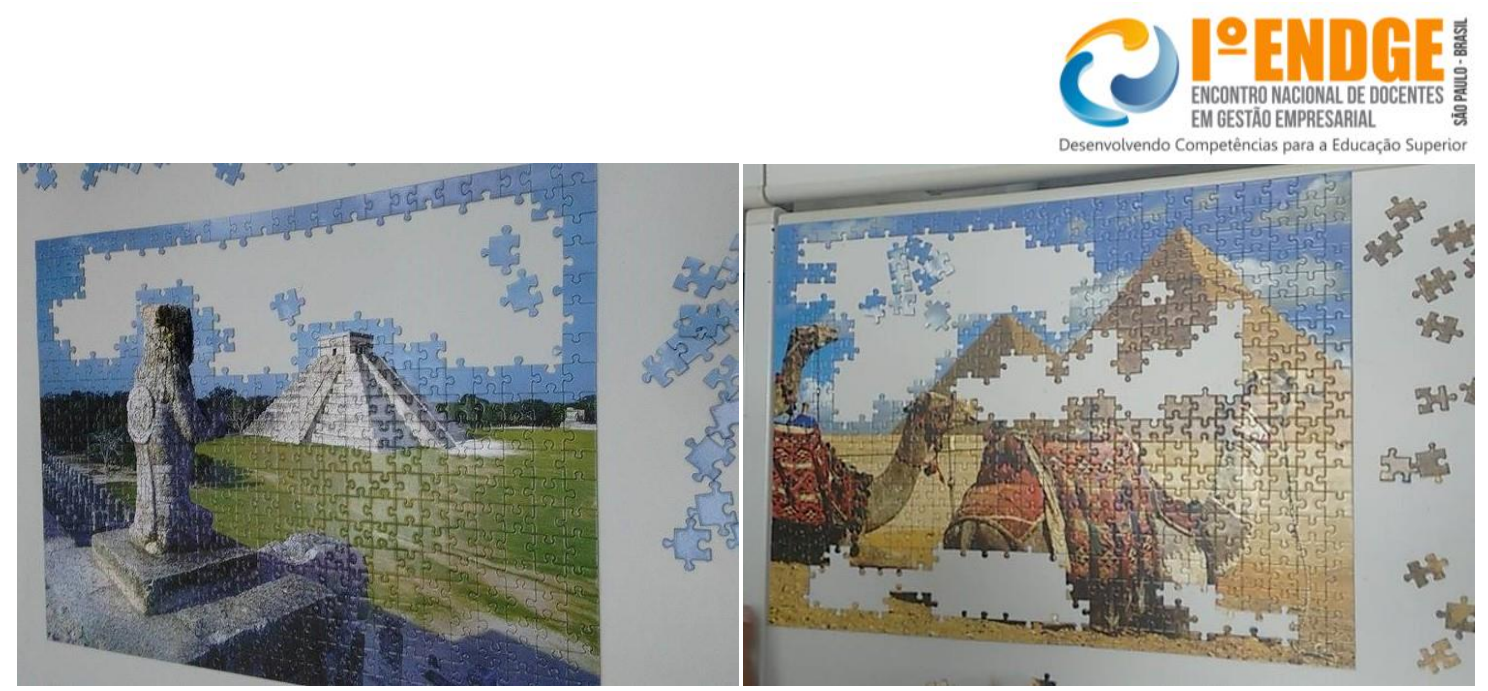

Figura 1: Final da montagem do quebra-cabeça realizada pelo Grupo A e B.

Como última atividade da disciplina, os acadêmicos deveriam e realizar a proposta completa de um curso de extensão na modalidade de Ensino à Distância $(\mathrm{EaD})$. Um formulário deveria ser entregue incluindo colaboradores, estudantes, vigência, cronograma (planejamento, execução, avaliação e relatório), orçamento das diversas categorias de materiais indicando fonte, valor e quantidade, e, ainda, um projeto que contivesse de forma reduzida: objetivos, revisão bibliográfica, materiais e métodos necessários.

Como pode ser percebido, para a conclusão deste trabalho, os alunos tiveram que aplicar todos os conhecimentos adquiridos durante o período letivo, além de noções de gestão de recursos, elaboração de planos, metodologias didáticas para o ensino a distância e formas de avaliação da aprendizagem.

\section{Discussão}

Os resultados obtidos com o planejamento adotado e a metodologia aplicada se relacionam a melhorias de comportamento pessoal e interpessoal, familiaridade com a profissão e conhecimento da prática de gestão. Dentre as melhorias citadas destacam-se, respectivamente:

- Apresentação de trabalho, domínio de público, trabalho em grupo;

- Contato com profissional experiente para perguntas, tira-dúvidas e contato com o dia a dia da profissão;

- Estudo de opções levando em consideração limitações financeiras; gestão de tempo, recursos e pessoas; competições e problemas do relacionamento diário de profissionais com formação em áreas distintas; escrita, discussão e proposta de solução.

Ainda sobre os benefícios obtidos, a apresentação de propostas em sala de aula por parte dos alunos envolveu situações onde os alunos eram instigados a defender ou criticar as escolhas uns dos outros, provocando como efeito colateral a melhoria na apresentação e domínio de público.

No decorrer das atividades, notou-se que exposições rápidas, em torno de 3 minutos favoreceram o desenvolvimento das dinâmicas e estas otimizaram a aprendizagem. Ao final, ficou claro que agora eles conhecem muito mais possibilidades de softwares e hardwares, mas também as estruturas e necessidades das escolas da região.

Percebeu-se que, apesar de intenso, o período letivo foi extremamente produtivo e proveitoso para todos os envolvidos. Um fato que pode ser constatado é que estes graduandos não terão as mesmas dificuldades comumente identificadas na proposição de atividades de extensão, na relação com burocracias e na execução de atividades administrativas, gerenciais e seus cargos e funções. 


\section{Considerações Finais}

Neste trabalho foram apresentados conteúdos que influenciaram na escolha de abordagem e adaptação da ementa da disciplina de Gestão de Tecnologias na Educação ministrada para o oitavo período do curso de Computação na Universidade Federal Fluminense, campus de Santo Antônio de Pádua, RJ.

Estão indicadas as metodologias adotadas para apresentação do conteúdo e as atividades que foram solicitadas aos acadêmicos.

A disciplina visou fornecer o contato inicial com planejamento, organização, avaliação, gestão e promoção de soluções tecnológicas, não deixando de lado as burocracias, setores e a diversidade de funções exercidas.

A ênfase em situações do dia a dia, aliada a busca por documentação, debate com gestor da região e os alunos foram incentivados a propor três soluções para cenários realistas do ensino básico, técnico e superior.

Considera-se que este trabalho inicia um debate sobre a necessidade de formação de gestores nos cursos de graduação, apresenta uma alternativa para ser discutida e aprimorada, mas que possui contribuições com resultados aplicados e alternativas didáticas que melhoraram de forma significativa o conhecimento dos alunos e teve ampla aceitação e engajamento.

\section{Referências}

BROUGÈRE, Gilles. Brinquedo e Cultura. $3^{\mathrm{a}}$ edição. São Paulo, Cortez, 2000.

DAMASCENO, Laíze. Marketing de Gentileza. Rio de Janeiro: Brasport, 2015.

MEC: Referenciais de qualidade para educação superior à distância. 2007. Disponível em http://portal.mec.gov.br/seed/arquivos/pdf/legislacao/refead1.pdf. Acesso em maio 2016.

MERCADO, L. P. L. Formação Docente e Novas Tecnologias. Novas Tecnoloigas na educação: reflexões sobre a prática. EDUFAL, Maceió, 2002.

WPENSAR1. Diretores no Brasil. Disponível em http://materiais.wpensar.com.br/infograficogestao-escolar, acesso em maio 2016.
WPENSAR2.
Perfil
dos
professores
no
Brasil.
Disponível em http://materiais.wpensar.com.br/infografico-perfil-dos-professores, acesso em maio 2016. 